\title{
Trabajo Social y medios de comunicación: perspectivas y posibilidades de encuentro
}

\author{
Mercedes Muriel-Saiz \\ Graduada en Trabajo Social. Máster Oficial en Trabajo Social \\ Universidad Complutense de Madrid. Madrid, España \\ https:// orcid.org/0000-0002-2172-0010 •
}

\author{
Maribel Martín-Estalayo \\ Diplomada en Trabajo Social. Doctora en Trabajo Social \\ Universidad Complutense de Madrid. Madrid, España \\ https://orcid.org/0000-0003-3683-1327 • mmestalayo@ucm.es
}

\section{Resumen}

El siguiente artículo es una revisión de la literatura científica y profesional que permite identificar la relación existente entre los medios de comunicación y el Trabajo Social. Si bien se trata de un campo poco desarrollado, las investigaciones internacionales y nacionales coinciden en reconocer el impacto social y el poder que los medios de comunicación ejercen en la construcción y proyección de la profesión de Trabajo Social y, a su vez, se observa en ocasiones cómo esta imagen se vulnera por falta de conocimiento o sensibilidad. Una idea eje que atraviesa todo el argumento es que mantener la distancia y una actitud de ignorancia mutua no es sólo una cuestión de imagen, sino que repercute significativamente en el vínculo que se establece entre la trabajadora social y el sujeto de intervención en un contexto institucional. Trabajar por una imagen más ajustada a la realidad es una tarea educativa urgente y un deber para con la profesión y la ciudadanía.

Palabras clave: Trabajo Social; Medios de comunicación; Imagen profesional.

Recibido: 29/01/2020 | Aprobado: 18/05/2020

Esta obra está bajo una Licencia Creative Commons Atribución-NoComercial-CompartirIgual 4.0 Internacional.

Procedencia del artículo: Artículo asociado a una tesis doctoral del Programa de Doctorado de Trabajo Social de la Universidad Complutense de Madrid. La investigación se encuentra en curso.

¿Cómo citar este artículo? / How to quote this article?

Muriel-Saiz, M., y Martín-Estalayo, M. (2020). Trabajo Social y medios de comunicación: perspectivas y posibilidades de encuentro. Prospectiva. Revista de Trabajo Social e intervención social, (30), 23-40. doi: 10.25100/ prts.v0i30.8852. 
Muriel-Saiz y Martín-Estalayo

\title{
Social Work and the Mass Media: Perspectives and Possibilities of Encounter
}

\begin{abstract}
The following article is a review of the scientific and professional literature that identifies the relationship between mass media and Social Work. Although it is a field that is not very developed, international and national research coincides in recognizing the social impact and the power that the media exerts in the construction and projection of Social Work as a profession and, at the same time, it is sometimes observed how this image is violated due to lack of knowledge or sensitivity. A central idea that runs through the whole argument is that maintaining distance and an attitude of mutual ignorance is not only a question of image but has significant repercussions on the link that is established between the social worker and the subject of intervention in an institutional context. Working towards an image more in line with reality is an urgent educational task and a duty towards the profession and the public.
\end{abstract}

Keywords: Social Work; Mass media; Professional image.

Sumario: 1. Introducción, 2. Metodología, 3. Hallazgos, 3.1 Medios de comunicación y opinión pública: elementos para la configuración de la imagen profesional, 3.2 La imagen de la trabajadora social en la televisión: un papel secundario y dramático, 3.3 La oportunidad profesional de ser objeto y sujeto de interés mediático, 3.4 Relaciones tímidas, puntuales y significativas entre el Trabajo Social y los medios de comunicación: el caso de España, 4. Conclusiones, 5. Referencias bibliográficas. 


\section{Introducción}

Este artículo tiene por objeto analizar la relación que se establece entre las profesionales del Trabajo Social y la imagen que de ellas se proyecta en los medios de comunicación. Partimos de una premisa: el tratamiento de la imagen de las trabajadoras sociales en los medios de comunicación es escaso y superficial. Y, además, se observa un mayor interés en visibilizar el Sistema Público de Servicios Sociales, espacio donde hay una gran representación profesional -aunque no el único y el que mejor permita, en ocasiones, representar la profesión- difuminándose en el tratamiento del hecho noticioso las fronteras entre sistema y profesión.

En cuanto a las percepciones y las opiniones de las trabajadoras sociales acerca de su práctica profesional, se aprecia un mayor estudio. Existen investigaciones relacionadas con las condiciones laborales de estas profesionales, la responsabilidad ética en su ejercicio profesional, la supervisión profesional, la importancia de la formación continua, el trabajo en red con otras instituciones, el síndrome de desgaste profesional (burnout), los contextos de intervención, su identidad como profesionales, etc. Sin embargo, no hay un desarrollo posterior que vincule las percepciones y el reconocimiento de estas profesionales y la imagen que de ellas se construye en los medios de comunicación.

Así, este artículo pretende poner el foco en el proceso que acontece entre la imagen profesional y los medios de comunicación como generadores de opinión pública. De aquí prenderá la idea de la necesidad de plantear espacios de encuentro y de diálogo entre las trabajadoras sociales y quiénes elaboran contenidos noticiosos en los medios de comunicación. Esta interlocución, o su ausencia, forma parte irremediable de la opinión pública y del imaginario colectivo existente sobre la profesión; afecta directamente al reconocimiento social percibido y atribuido de las trabajadoras sociales; $\mathrm{y}$, fundamentalmente, ensombrece o invisibiliza las posibilidades y aportes de esta profesión para la ciudadanía.

\section{Metodología}

El desarrollo de esta investigación se ha realizado a partir de una revisión documental exhaustiva y profusa de los estudios previos existentes que analizan la presencia de informaciones noticiosas relacionadas con el Trabajo Social en los medios de comunicación. 
Muriel-Saiz y Martín-Estalayo

Relacionado con los criterios de selección de las investigaciones se ha elaborado un estado de la cuestión que ha tratado de recoger todas aquellas investigaciones existentes tanto en lengua española como en lengua inglesa de artículos, libros o contribuciones a espacios de reflexión de estudios que analizaran la imagen de la profesión del Trabajo Social en los medios de comunicación. La búsqueda se realizó en el periodo de tres meses -durante el curso 2019- en diferentes bases de datos y repositorios digitales de contenido científico, así como en recursos de acceso libre y de interés profesional para trabajadores y trabajadoras sociales.

La posterior selección de la muestra del total del material obtenido se ha realizado a partir de la organización de las investigaciones en base a criterios tales como: lengua en la que se están realizadas, fecha de publicación y posibilidad (o no) de acceso online al texto completo.

Cabe mencionar que estas investigaciones o trabajos provienen tanto del contexto español como del anglosajón, donde destacan de una manera significativa los avances y aportaciones de investigadoras neozelandesas.

\section{Hallazgos}

\subsection{Medios de comunicación y opinión pública: elementos para la configuración de la imagen profesional}

Estudiar la imagen que proyectan los medios de comunicación es una cuestión que ha suscitado numerosos análisis y atenciones desde distintos espacios. Otras disciplinas y profesiones como la Educación, la Enfermería, la Medicina, el Derecho, la Psicología o el propio Periodismo ya han realizado este ejercicio. De la misma forma, se han trabajado diversos temas tales como la violencia machista, la prostitución, la desprotección infantil, el sin hogarismo, la salud mental, etcétera; o estudios de imagen sobre países: China, Rusia o Marruecos; y también la imagen de instituciones como pueden ser centros de salud, bibliotecas, universidades, hospitales, organismos europeos, etcétera.

En el caso concreto de España, aunque sí se ha estudiado la imagen del Trabajo Social de manera indirecta a través de investigaciones doctorales sobre la profesionalización del mismo o su identidad, elementos que también afectan a la configuración de esta imagen, apenas hay producción científica de la relación planteada Trabajo Social-medios de comunicación. En este sentido, la interacción entre 
medios de comunicación y Trabajo Social se ha desarrollado con mayor atención en el mundo anglosajón, puesto que ya han entendido desde hace décadas lo siguiente:

La representación de la profesión del Trabajo Social que aparece en los medios de comunicación tiene un impacto en la conducta y en la práctica profesional, influye también sobre el público por lo que se cuenta de las trabajadoras sociales. Estas representaciones influyen en el estado de ánimo de la opinión pública sobre la profesión porque en última instancia, esta representación en los medios de comunicación afecta a la política social relativa a los servicios sociales, a las trabajadoras sociales y a los usuarios. (Zugazaga, Surette, Méndez \& Otto, 2006, p. 622).

Ya en la década de los noventa se preocuparon especialmente por la imagen que se reflejaba en la prensa escrita como medio de comunicación hegemónico de aquel momento. Así pues, se pueden encontrar numerosos estudios científicos que abordan este aspecto. Destaca Aldridge (1990) con su artículo Social Work and the News Media: A hopeless case? donde se apunta la queja y el malestar de las trabajadoras sociales por la imagen distorsionada que se publica de su labor en los medios de comunicación, siempre referidas a desastres sociales o a prácticas de voluntariado. A la vez, se pone de manifiesto mediante ejemplos de cobertura positiva, que las historias e informaciones más positivas y ajustadas a la realidad se reflejan, sobre todo, en la prensa local. Lo local permite un acceso y un trato más directo con las trabajadoras sociales que lo alejan de los extendidos estereotipos. En esta línea, ya en la década de los noventa se plantea el papel de los colegios profesionales y de las instituciones profesionales del Trabajo Social para contribuir a generar otro tipo de informaciones. Esta misma autora dedicó un libro a los medios y el Trabajo Social: Aldridge (1994) Making Social Work News, donde expone casos concretos de Trabajo Social y cómo ha sido el tratamiento informativo de estos sucesos por parte de los medios de comunicación.

En la década de los noventa hay también trabajos como el de Franklin \& Parton (1991) con el libro Social Work, the Media and Public Relations, donde se realiza una investigación en profundidad sobre la situación del Trabajo Social y los medios de comunicación; analiza cómo estos construyen la imagen y las imágenes del Trabajo Social y la complejidad para establecer relaciones entre ambas profesiones; y explora estrategias para ir más allá de la cobertura mediática negativa. Asimismo, sugiere ideas que recogerán estudios de décadas posteriores como, por ejemplo, que las trabajadoras sociales consideran que los periodistas carecen de los conocimientos suficientes y de la sensibilidad necesaria para informar de manera adecuada sobre la profesión. Y a su vez, los periodistas consideran que las trabajadoras sociales 
Muriel-Saiz y Martín-Estalayo

desconocen la estructura y el funcionamiento organizacional de los medios de comunicación. Es más, en este libro se muestra cómo los periodistas responsabilizan a las trabajadoras sociales de muchas de las informaciones que se publican, acusándolas de no establecer una relación proactiva en la difusión de una imagen profesional más positiva.

A partir del segundo milenio destaca el trabajo de Tower (2000), que muestra preocupación por el abandono de las trabajadoras sociales con respecto a los medios de comunicación de cara a moldear la opinión pública. Propone introducir en el currículo académico de la formación en Trabajo Social el estudio de los medios, concretamente enseñar a las futuras trabajadoras sociales nociones de televisión para transmitir otra imagen alternativa a la imagen mediática tradicional. "Enseñar a los estudiantes a configurar la imagen pública del Trabajo Social a través de un uso efectivo de los recursos de los medios de comunicación supone una innovación educativa que abordará el problema de la imagen profesional y ayudará a cumplir esta parte de la misión de la profesión en el siglo XXI" (p. 575). Han pasado casi veinte años desde este artículo y la introducción de nociones básicas sobre medios de comunicación sigue siendo una utopía en el currículo académico de las futuras trabajadoras sociales.

Un año más tarde, Reid \& Misener (2001), abordan nuevamente la relación de las trabajadoras sociales en la prensa con especial hincapié en la importancia de producir imágenes adecuadas de la profesión. A partir de un análisis de 258 noticias de Estados Unidos y 141 noticias de Reino Unido llegan a la conclusión de la abundancia de noticias negativas en torno a las profesionales del Trabajo Social, especialmente en lo que refiere a la protección de la infancia donde siguen apareciendo como las "quita niños". Las autoras proponen realizar una labor explicativa hacia las profesiones de la información para que entiendan mejor las intervenciones sociales. Se apuesta por informar no solo sobre retiradas de tutela como forma predominante sino también sobre proyectos de intervención social innovadores, así como presentar a las profesionales como expertas en determinados ámbitos como el de la exclusión social, la salud mental o la protección a la infancia. Si bien es cierto que las noticias positivas no abundan en una profesión dedicada al sufrimiento y dificultad social, su falta de difusión o la forma en la que se trata tiene un impacto en el público. Así lo aseveran en el estudio:

No se puede saber hasta qué punto el peso de las noticias positivas compensan o suavizan las historias negativas. Ahora bien, también hay que considerar que desafortunadamente el Trabajo Social no suele producir historias positivas con capacidad para influir en el público como si lo hacen las negativas. (p. 199). 
Muriel-Saiz y Martín-Estalayo

Otros estudios anglosajones que abordan los medios de comunicación en relación con la práctica profesional del Trabajo Social son la reflexión teórica de Westwood (2013), que pone el foco en la relación que se establece históricamente en los medios de comunicación de las trabajadoras sociales con la función de protección a la infancia. En este trabajo se explica el complejo entramado que supone ofrecer información y tener especial cuidado con la protección de datos y la confidencialidad. En este sentido, muchas veces los periodistas solicitan datos concretos de los casos que no pueden ser ofrecidos en virtud del secreto profesional. Este hecho afecta a la elaboración de las informaciones noticiosas. Por último, esta misma autora entiende la comunicación corporativa del Trabajo Social como una nueva forma de proyección laboral para las trabajadoras sociales, como una posibilidad de nuevos espacios profesionales en una sociedad cada vez más preocupada por la información. A su vez, esta misma autora ha trabajado la importancia de las redes sociales para la educación del Trabajo Social como un altavoz donde dar a conocer la práctica profesional a un amplio público en su libro Social Media in Social Work Education (2014).

\subsection{La imagen de la trabajadora social en la televisión: un papel secundario y dramático}

En Gibelman (2004), encontramos el artículo sobre la televisión y la imagen pública de las trabajadoras sociales, Television and the Public Image of Social Workers: Portrayalor Betrayal? En un primer momento la autora se pregunta si la proliferación de la presencia secundaria de trabajadoras sociales en series televisivas está relacionada con una mayor sensibilización de la sociedad hacia la tarea profesional de éstas y su necesidad de mejorar la imagen pública. Sin embargo, descubre que en repetidas ocasiones las trabajadoras sociales aparecen en las series con imágenes negativas, "la televisión tiende a transmitir un mensaje antiprofesional, irrespetuoso con la imagen de las trabajadoras sociales. El mensaje que lanza es que no se necesita formación para hacer ese trabajo, como que cualquiera pudiera hacerlo" (p. 332). Tras el análisis de cuantiosas series en el contexto televisivo estadounidense, sostiene que la reproducción de estereotipos donde se confunde la labor técnica con el trabajo voluntario funciona entre la audiencia televisiva. Sin embargo, esta reproducción de estereotipos alejados de la realidad, afectan directamente a la imagen social de la profesión, más si consideramos la fuerte influencia de las series televisivas en la población más joven.

Los mensajes que se lanzan sobre trabajadoras sociales no cualificadas perpetúan el bajo estatus de la profesión, reforzando estereotipos y corroborando las representaciones sociales de lo que supuestamente hacen las trabajadoras sociales. Esto puede tener 
efectos para la población más joven como los adolescentes porque puede disuadir a potenciales estudiantes de la profesión. Este tipo de imágenes se difunden en la televisión semana tras semana, año tras año, generando una fuente de información duradera y muy poderosa para la construcción de imágenes que más que celebrar la profesión, la denigran. (Gibelman, 2004, p. 333).

Dos años más tarde, Zugazaga et al., 2006, llevaron a cabo un estudio exploratorio sobre las percepciones de las trabajadoras sociales de las imágenes que de estas aparecen en los medios de comunicación. Para ello, analizaron 665 encuestas a profesionales del Trabajo Social en Florida (Estados Unidos), todas ellas integrantes de la Asociación Nacional de Trabajadores Sociales de Florida. La principal novedad que aporta este estudio es que, hasta el momento, las investigaciones se habían centrado en la relación entre Trabajo Social y medios de comunicación, especialmente en cómo el público en general ve a la profesión a partir de los contenidos que proyectan los medios de comunicación. Sin embargo, en este estudio las autoras han ido un paso más allá y han preguntado a las propias trabajadoras sociales sobre cómo ellas observan y valoran su imagen profesional en los medios de comunicación. En este sentido, las trabajadoras sociales que participaron en el estudio sienten que la imagen profesional que aparece en los medios de comunicación es negativa, especialmente en las noticias. Estas profesionales entienden que su imagen es algo más positiva en los contenidos de entretenimiento como series o películas. "Los medios de comunicación de entretenimiento fueron percibidos por las trabajadoras sociales encuestadas como más amables en el retrato profesional, piensan que aparecen como más cariñosas" (p. 627).

En este recorrido por los estudios sobre Trabajo Social y medios de comunicación, destaca el estudio de Henderson \& Franklin (2007), Images of Social Care Professionals in Popular UK television Drama, cuyas autoras ya abordaron previamente la imagen de las trabajadoras sociales en la prensa. En este trabajo, van un paso más allá y deciden analizar la imagen de las trabajadoras sociales en las series televisivas de Reino Unido. Para ello desarrollaron durante 2003 un análisis de contenido de 249 episodios de series televisivas examinando cuál es el papel, el rol, las cualidades y el posicionamiento de estos personajes ficticios en las series. Si bien es cierto que las trabajadoras sociales vuelven a aparecer relacionadas con la protección a la infancia (disputas por la custodia de menores, acogida, adopción, malas pautas de cuidado materno/paterno, etcétera), los hallazgos de este estudio son novedosos en tanto que en las series televisivas las profesionales del Trabajo Social aparecen caracterizadas como profesionales comprensivas, cercanas y con capacidad de escucha. Sin embargo, también se retrata la burocratización de sus funciones, así como el aislamiento social que tienden a sufrir a causa de las complicadas decisiones que en muchas ocasiones 
deben tomar. Además, estas autoras identificaron que el tratamiento del personajetrabajadora social suele aparecer siempre vinculado al problema concreto y de forma secundaria, sin ser abordado en profundidad ni desarrollarse.

Una vez resuelto el problema, estos personajes dejan la trama. Su papel profesional funciona para un hecho determinado y no pasan a ser personajes complejos. La consecuencia de esto es que los espectadores rara vez pueden comprender en profundidad los dilemas y las dificultades a nivel emocional que atraviesan las trabajadoras sociales a la hora de trabajar. Las preocupaciones de las tramas siempre giran en torno a los personajes principales, y las trabajadoras sociales pueden aparecer como profesionales cercanas, simpáticas, pero no se involucran con la trama central de la serie. (p. 148).

\subsection{La oportunidad profesional de ser objeto y sujeto de interés mediático}

Algunas de las investigaciones señalan los espacios que procuran los medios de comunicación como la oportunidad que tiene el Trabajo Social de aclarar su imagen social y, en consecuencia, poder transformar los contextos donde se llevan a cabo sus intervenciones. En el contexto británico Jones (2012) en su artículo Child protection, Social Work and the media: doing as well as being done to, analiza lasnoticias que dan cobertura a la protección a la infancia desde 2008 hasta 2010 y cómo es la imagen de las trabajadoras sociales en relación a esta labor. La influencia de los medios de comunicación en el abordaje de la protección a la infancia puede incluso generar cambios en los sistemas especializados de intervención ante determinadas situaciones. Este artículo pone de manifiesto que en el contexto mediático de protección a la infancia las trabajadoras sociales suelen tener un papel protagonista, pero que las informaciones reflejan una falta de confianza en estas profesionales, proyectando con mucha frecuencia imágenes sesgadas o negativas sobre la práctica profesional. El autor alude, como ya se ha señalado en estudios previos, a la necesidad de ser proactivos en la relación con los periodistas y explica la importancia de aprovechar la coyuntura para explicar la complejidad del sistema de protección a la infancia, así como las dificultades en la toma de decisiones de estos casos a los que se enfrentan. De hecho, este autor refiere que aunque las noticias sean negativas, las trabajadoras sociales no deben perder la oportunidad de conseguir espacios en los medios de comunicación. "Es una oportunidad muy grande para dejar de ver a la profesión del Trabajo Social como una amenaza y explicar el trabajo que se hace para proteger a los niños" (p. 90). 
Por su parte, Stanfield \& Beddoe (2013) en Nueva Zelanda han trabajado en numerosas ocasiones los efectos de los medios de comunicación en las percepciones sociales del público como un elemento más en la configuración de la imagen social de la profesión. De todos sus trabajos, resulta interesante destacar el estudio que aborda las posibilidades que ofrece establecer una colaboración formativa entre los medios de comunicación y el Trabajo Social. Se trata de un proyecto educativo piloto que sitúa en un mismo espacio docente a futuras trabajadoras sociales y a futuras periodistas. La propuesta persigue formar para la sociedad periodistas sensibles y conocedoras de la realidad social y, por parte, trabajadoras sociales conscientes del poder e influencia de los medios de comunicación. Estas autoras entienden que estar del lado de quienes informan, va a generar fácilmente un cambio $\mathrm{y}$, además, se pueden convertir en expertas informantes. De hecho, pareciera que es una propuesta necesaria y según las autoras "establecer relaciones entre medios de comunicación y Trabajo Social, no es nada nuevo en tanto que las pioneras de la profesión ya establecían hace años relaciones de este tipo para comunicar la profesión" (p.44). Pero en la actualidad apenas existen este tipo de colaboraciones interprofesionales.

En este recorrido por las oportunidades que se desprenden de la relación profesional entre trabajadoras sociales y medios de comunicación parece reseñable explicar que el periódico británico The Guardian cuenta con una sección titulado Social Care Network, donde se publican entradas con cierta regularidad para explicar en profundidad la atención social en Reino Unido. En este blog con frecuencia se generan contenidos acerca de la imagen de las trabajadoras sociales en los medios. Ejemplo de ello sería la entrada titulada $A$ warped view of Social Work in the media in unfair and dangerous de Mason (2018), donde se alerta sobre las consecuencias de proyectar una imagen negativa de las prácticas de estas profesionales así como promover la desconfianza en las personas usuarias de los sistemas de protección social. También nos sirve la entrada bajo el título de Why can't social workers share success stories with the media? de Niven (2017) donde se manifiesta la tendencia a contar sucesos negativos o escabrosos relacionados con trabajadoras sociales cuando diariamente experimentan y son testigo de historias de coraje y superación con las personas usuarias. Este blog podría ser un ejemplo de buena práctica en la difusión mediática de la práctica profesional del Trabajo Social. Pues no se trata de idealizar la profesión, pero sí de aportar una imagen adecuada y ajustada a la realidad: "una imagen positiva es importante para la vitalidad y efectividad de la profesión. Cuanto más se perciba positivamente el Trabajo Social, más probable será obtener apoyo para sus programas, utilizar sus servicios, mantener la moral, atraer a los interesados y hacer oír su voz" (Kaufman \& Raymond, citados en Reid \& Misener, 2001. p. 194). 


\subsection{Relaciones tímidas, puntuales y significativas entre el Trabajo Social y los medios de comunicación: el caso de España}

A nivel nacional se constata una ausencia considerable de estudios acerca de los medios de comunicación y el Trabajo Social, si bien es cierto el Sistema Público de Servicios Sociales ha suscitado un interés algo mayor que la profesión en las investigaciones sobre la comunicación. En este sentido, José Ramón Bueno-Abad (1996) es uno de los precursores sobre el tema de la imagen de los Servicios Sociales en los medios de comunicación (concretamente, la prensa escrita). Su libro Los servicios sociales en la prensa escrita, estudia la imagen y las representaciones en los medios a partir de un análisis de los periódicos valencianos de mayor influencia. Se trata de un estudio novedoso, realizado entre 1990 y 1992, coincidiendo con un momento de expansión y desarrollo del Sistema de Servicios Sociales. Este mismo autor constata que la influencia de los medios en la construcción del imaginario social es evidente. Y más adelante continúa su desarrollo en el artículo titulado Representaciones sociales e interacción social: una perspectiva crítica sobre el efecto de los mass media (Bueno-Abad y Mestre-Luján, 2003).

No se han publicado hasta el momento más trabajos de análisis de contenido en prensa relacionados con la imagen del Trabajo Social como objeto de estudio; sí algunos estudios que abordan problemáticas sobre las que el Trabajo Social suele intervenir, como la tesis de Mestre-Luján (2002) donde observa la imagen de la enfermedad mental en la prensa escrita con la sugerente idea de estudiar los titulares de la locura, o un breve artículo de Marinas- Sánchez (1999) sobre La imagen de los desviados, excluidos y otros herejes en la prensa.

Anteriormente hemos hecho alusión al espacio del Trabajo Social en la televisión. Bien, en esta década de los 90, encontramos una experiencia inusual que nos sumerge de lleno a conocer y valorar las posibilidades del Trabajo Social en el desarrollo de un programa televisivo de sucesos. El conocido programa Quién sabe dónde del director Paco Lobatón, contaba entre sus expertos con un psicólogo, un asesor jurídico y una trabajadora social. Fernanda Jiménez-Alfaro (1997), autora del artículo y trabajadora social en dicho programa, nos descubre, bajo el lema de la "experiencia justifica la presencia", el día a día y las funciones de su tarea. Entre otras, se destacan: investigar, orientar y asesorar el tratamiento televisivo de aquellos contenidos en los que se precisa de intervención social; conectar y comunicarse con las instituciones, públicas y privadas; informar a las instancias pertinentes sobre las situaciones de riesgo que se han detectado durante la investigación; coordinar con el equipo de dirección y realización la intervención y seguimiento de un caso. Todo ello da cuenta del potencial y aporte de la profesión para el asesoramiento de un tipo de contenido televisivo. 
Muriel-Saiz y Martín-Estalayo

A finales de los noventa Gallego-Ayllón (1999) se aproxima de manera descriptiva al contexto sociopolítico de los Servicios Sociales a través de la prensa. Sin embargo, un libro de referencia para la comunicación en temas sociales es el de GarcíaHerrero y Ramírez-Navarro (2001) titulado Imagen y comunicación en temas sociales donde analizan la trayectoria de la imagen en los Servicios Sociales, en los congresos estatales de Trabajo Social, así como sus propuestas en torno a las estrategias de comunicación en temas sociales y posibles acciones a desarrollar en campañas publicitarias.

Pérez-Cosín (2003) en su tesis doctoral El Trabajo Social, sus imágenes y su público: la construcción de una identidad colectiva dedica el capítulo tercero a la influencia de los medios de comunicación y cómo estos generan representaciones sociales que acaban influyendo en el imaginario colectivo de la sociedad. En este sentido, analiza la influencia de la serie de RTVE, Raquel busca su sitio ${ }^{1}$, que entre los años 2001 y 2002 emite 25 capítulos de la única serie española hasta el momento que narra las peripecias de una trabajadora social y sus compañeros profesionales en un centro de Servicios Sociales.

Poco a poco en España se está tomando conciencia de la importancia de estudiar, analizar y proyectar una imagen adecuada en los medios de comunicación, en tanto que generadores de opinión pública y alta influencia. Por ello, empiezan a emerger investigaciones que apuestan por prestar atención y trabajar en la elaboración de planes estratégicos de comunicación, sobre todo en el contexto estigmatizado del Sistema Público de Servicios Sociales. Asimismo, se dedican volúmenes temáticos en revistas profesionales como el número 48 con un monográfico sobre "Imagen, comunicación e intervención social" del Consejo General del Trabajo Social (1999), y el número 92 de la revista Servicios Sociales y Política Social del Consejo General del Trabajo Social (2010) en España. Este número contiene artículos donde profesionales, tanto del ámbito público o privado, narran sus experiencias y reflexiones en torno a los procesos de comunicación en la intervención social, recordándonos que es una tarea pendiente.

Debemos posicionar al trabajo social y a los servicios sociales a través de los medios de comunicación, a través de una comunicación efectiva, aprovechando los recursos que nos ofrecen las Tecnologías de la Información y comunicación, porque como bien dice el título de uno de los artículos: el que no se mueve no sale en la foto, y si no sales en la foto no existes. (p.6).

1 La serie contó con el asesoramiento del Consejo General de Trabajo Social de España. 
Muriel-Saiz y Martín-Estalayo

En la tesis de Baltar-Moreno (2012) con el título Difusión y promoción de los Servicios Sociales públicos: los Servicios Sociales de atención primaria: diagnóstico y percepciones desde los actores institucionales, se realiza un exhaustivo estudio sobre el nivel de difusión y conocimiento de los Servicios Sociales de la Comunidad de Madrid y la importancia de generar campañas y planes de comunicación para romper la barrera de la desinformación. Se trata de una investigación muy valiosa por su profundización en la comunicación en los Servicios Sociales, considerando la comunicación institucional, la comunicación en la Administración, la comunicación en servicios públicos y, sobre todo, la comunicación y el uso de las nuevas tecnologías como una estrategia de mejora para el sistema de Servicios Sociales. Este mismo autor ha realizado varias publicaciones destacando el artículo Comunicación y conocimiento de los Servicios Sociales Públicos. La difusión de los Servicios Sociales municipales en la Comunidad de Madrid (2014), donde expone de manera sistemática los resultados más significativos de su trabajo doctoral. Por ejemplo, señala la difusión limitada y confusa que sobre Servicios Sociales está llegando a la ciudadanía española, debido a una escasa o inexistente inversión en publicidad y comunicación por parte del sistema. En palabras del autor, el desconocimiento tiene además dos consecuencias: la primera de ellas tiene que ver con la confusión que se genera por parte de la ciudadanía con respecto a Servicios Sociales y, la segunda, justifica cómo este desconocimiento preserva la estigmatización histórica existente de determinados sectores respecto a la percepción general del conjunto del sistema.

Con la llegada del nuevo milenio y el auge de Internet, las redes sociales y las técnicas de mercado para el ámbito de lo social, así como la estabilización de los estudios universitarios de marketing, surgen algunas recomendaciones sobre el uso de estrategias de marketing en centros de Servicios Sociales. Se trata de propuestas interesantes en tanto que ponen de relieve la importancia de dar a conocer las prácticas profesionales de los Servicios Sociales como forma de democratizar esa información y de llegar a más personas, pues al fin y al cabo el Sistema de Servicios Sociales debiera tener una pretensión y horizonte universalista. Es sugerente poder pensar el marketing como algo que va más allá del beneficio económico, sin embargo, existe el riesgo de caer con facilidad en cierto exhibicionismo y, en algunos casos, en una mercantilización de la protección social. Todo ello sin un posicionamiento y reflexión sobre la garantía de derechos sociales, las prácticas profesionales, las dinámicas de este sistema y sus límites o posibilidades. Ejemplo de estos riesgos se presentan en el libro de Paz Membrire-Saavedra (2012) donde traslada el marketing y la comunicación al ámbito de los Servicios Sociales como si de un recetario se tratara sin un profuso análisis del contexto y sus intervinientes. 
Muriel-Saiz y Martín-Estalayo

Es común constatar que los estudios acerca de la aplicación de técnicas de marketing en Servicios Sociales se adaptan mucho más a la intervención social del ámbito empresarial o lucrativo, y no tanto a la de la Administración pública. Ejemplo de esta aplicación de las técnicas del marketing puede ser la tesis de Fariña-Santos (2016) titulada El marketing público en la gestión de los Servicios Sociales municipales de Galicia: estudio de caso. Se trata de un trabajo principalmente descriptivo y exploratorio donde analiza la posibilidad de aplicar técnicas de marketing en grandes municipios de Galicia, siendo esta posibilidad limitada precisamente por la dinámica del sector público. En esta misma línea, hay propuestas de marketing para los centros de personas mayores (San Miguel-Osaba y Allur-Aramburu, 2011),de cara a mejorar la atención ofrecida preguntando a los mayores residentes y a sus familiares sobre las percepciones e imágenes que poseen de los servicios recibidos. Asimismo, otra tendencia que imprime cierto riesgo con respecto a la aplicación del marketing y la comunicación en Servicios Sociales es asociarlo a la gestión de calidad y a la satisfacción de las personas usuarias, acabando en propuestas cuantitativas vacías de contenido, sin el necesario análisis que precisa la complejidad del Sistema Público de Servicios Sociales. Pues muchas de las propuestas pretenden aplicar técnicas de marketing y venta -a través de encuestas de calidad y satisfacción- cuyo principal objetivo es mantener o suprimir programas en función de su rentabilidad y/o productividad. Esto deja fuera otro tipo de reflexiones en torno a la garantía de derechos sociales que debiera ser uno de los fines principales de la intervención social. Por consiguiente, si bien resultan interesantes porque permiten difundir el Trabajo Social desde una perspectiva novedosa, es conveniente mostrar cautela con estas nuevas derivas que llevan a asociar la comunicación con una aplicación del marketing vacío de contenido teórico y/o que no tiene en cuenta el contexto situado en el que se desarrolla la práctica profesional del Trabajo Social.

Antes de finalizar este punto, es interesante anotar de manera sucinta algunos de los trabajos que sobre este objeto inspiran en América Latina y están en esta línea de desarrollar puentes de colaboración entre los medios de comunicación y el Trabajo Social. Cabe mencionar a Chinchilla-Montes (2002) sobre el poder, los medios de comunicación y el Trabajo Social y Betancourt-Díaz (2014) sobre la influencia de los medios para las políticas sociales y el Trabajo Social en Puerto Rico. 


\section{Conclusiones}

El estudio desarrollado a lo largo de estas páginas permite dar cuenta de la necesidad de investigar, reflexionar y trabajar por mejorar la imagen del Trabajo Social en los medios de comunicación. Se trata de una tarea muy avanzada en el mundo anglosajón, tal y como se ha podido comprobar cuentan con estudios de análisis de contenido en prensa especialmente en la década de los noventa y principios de los dos mil. Esto les ha permitido profundizar más en otras cuestiones también relacionadas con el mundo de la comunicación, pero desde otros prismas, como el análisis de series televisivas, o la propia imagen de las trabajadoras sociales en medios digitales. El espacio mediático que el periódico The Guardian reserva en su blog para que las trabajadoras sociales puedan mostrar su conocimiento técnico sobre el cuidado social o la propuesta pedagógica piloto en Nueva Zelanda de formar a periodistas y trabajadoras sociales de manera conjunta, son muestras que ponen de relieve la fase en la que se encuentran con respecto al objeto de estudio planteado y nos señalan un despliegue de posibilidades.

En España la investigación en este ámbito se encuentra en un estadio básico de desarrollo. Y los estudios o propuestas halladas representan el impulso sobre la necesidad de estudiar, reflexionar y producir conocimiento sobre medios de comunicación y Trabajo Social. Se abre por tanto un necesario campo de investigación, que complemente los estudios previos citados y traten directamente la imagen que los medios de comunicación proyectan del Trabajo Social. Si entendemos que la investigación en Trabajo Social suele tener una pretensión operativa, será el conocimiento riguroso sobre qué imagen configuran los medios del Trabajo Social el primer paso para actuar sobre su contenido y, quizás, se puedan acortar distancias en la comprensión de las posibilidades, los riesgos y las limitaciones de la intervención social. No se debe olvidar que la percepción que las profesionales tienen de sí mismas está intrínsecamente relacionada con las imágenes que les llegan de fuera, y estas percepciones pareciera que están afectando de manera positiva o negativa en los procesos de intervención social.

Por último, entendemos que es importante construir una imagen corporativa en los medios de comunicación más cuidada, reflexionada y elaborada; proyectar unas representaciones sobre el Trabajo Social en consonancia con su objeto de estudio e intervención; pensar que la comunicación, en tanto que cuarto poder, influye y colabora en los cambios sociales. $Y$ es que lo que se desarrolla, se crea y se vive en el ejercicio de la práctica profesional del Trabajo Social, se revaloriza, se mejora y se extiende cuando se comparte. Por todo ello, es importante trabajar por una imagen más cotidiana y realista de la profesión con el público en general para fortalecer y adecuar el vínculo y las expectativas entre la profesional y la persona que acude o demanda un proceso atención social. 


\section{Referencias bibliográficas}

Aldridge, M. (1990). Social work and the news media: A hopeless case? British Journal of Social Work, 20, 611-625.

Aldridge, M. (1994). Making Social Work News. Londres, Reino Unido: Routledge.

Baltar-Moreno, A. (2014). Comunicación y conocimiento de los Servicios Sociales públicos. La difusión de los Servicios Sociales municipales en la Comunidad de Madrid. Cuadernos de Trabajo Social, 27(1), 127-138.

Baltar-Moreno, M. (2012). Difusión y promoción de los Servicios Sociales públicos: los Servicios Sociales de atención primaria: diagnóstico y percepciones desde los actores institucionales (Tesis doctoral). Universidad Complutense de Madrid, Facultad de Ciencias de la Información. Madrid, España.

Betancourt-Díaz, E. (2014). Trabajo Social y sus roles en el debate público sobre políticas sociales a través de los medios de comunicación en Puerto Rico. Cuadernos de Trabajo Social, 27(2), 417-427.

Bueno-Abad, J.R. (1996). Los servicios sociales en la prensa escrita. Valencia, España: NauLlibres.

Bueno-Abad, J.R., y Mestre-Luján, F. (2003). Representaciones sociales e interacción social: una perspectiva crítica sobre el efecto de los mass media. Arxius de Sociología, 9, 39-62.

Chinchilla-Montes, M. (2002). Poder, medios de comunicación social y Trabajo Social. En III Congreso Anual. Federación Nacional de Estudiantes y Egresados de Trabajo Social, Culiacán, México.

Consejo General del Trabajo Social. (1999). Imagen, comunicación e intervención social. Revista de Servicios Sociales y Politica Social, (48), 9-82.

Consejo General del Trabajo Social. (2010). Comunicación y Trabajo Social. Servicios Sociales y Política Social, (92), 9-147.

Fariña-Santos, M.B. (2016). El marketing público en la gestión de los Servicios Sociales municipales de Galicia: estudio de caso (Tesis doctoral). Universidad de Santiago de Compostela, Facultad de Ciencias Políticas y Sociales. Santiago de Compostela, España.

Franklin, B., \& Parton, N. (1991). Social work, the media and public relations. Londres, Reino Unido: Routledge.

Gallego-Ayllón, M.J. (1999). Aproximación al contexto sociopolítico de los servicios sociales a través de la prensa. Una experiencia de alumnos de Diplomatura de Trabajo Social. Revista de Enseñanza Universitaria, (14-15), 119-128.

García-Herrero, G., y Ramírez-Navarro, J.M. (2001). Imagen y comunicación en temas sociales. Madrid, España: Consejo General de Colegios Oficiales de Diplomados en Trabajo Social y Libro Certeza. 
Muriel-Saiz y Martín-Estalayo

Gibelman, M. (2004). Television and the Public Image of Social Workers: Portrayal or Betrayal? Social Work, 49(2), 331-334.

Henderson, L., \& Franklin, B. (2007). Sad Not Bad: Images of Social Care Professionals in Popular UK Television Drama. Journal of Social Work, 7(2), 133-153.

Jiménez-Alfaro, F. (1997). El Trabajo Social y los Medios de Comunicación. Trabajo Social Hoy, (15), 103-110.

Jones, R. (2012). Child protection, social work and the media: doing as well as being done to. Research, Policy and Planning, 29(2), 83-94.

Marinas-Sánchez, M. (1999). La imagen de los desviados, excluidos y otros herejes en la prensa. Cuadernos de Trabajo Social, (12), 33-45.

Mason, S. (2018). A warped view of social work in the media is unfair - and dangerous. The Guardian. Social Care Network. Recuperado dehttps:/ / www.theguardian.com/social-care-network/social-lifeblog/2018/may/16/media-social-work-press-state-children.

Membrire-Saavedra, P. (2013). Marketing y comunicación en los Servicios Sociales. Madrid, España: Editorial Grupo 5.

Mestre-Luján, F. (2002). Los titulares de la locura: análisis diferencial de la prensa escrita sobre la representación social de la enfermedad mental (Tesis doctoral). Universidad de Valencia. Valencia, España.

Niven, D. (2017). Why can't social workers share success stories with the media? The Guardian. Social Care Network. Recuperado de https:// www.theguardian.com/social-care-network/social-lifeblog/2017/oct/03/why-cant-social-workers-share-success-stories-media.

Pérez-Cosín, J.V. (2003). El Trabajo Social, sus imágenes y su público. La construcción de una identidad colectiva (Tesis doctoral).Universidad de Valencia, Facultad de Ciencias Sociales. Valencia, España.

Reid, M.J., \&Misener, E. (2001). Social work in the press: a cross national study. International Journal of Social Welfare, 10(3), 194-201.

San Miguel-Osaba, E., y Allur-Aramburu, E. (2011).Marketing de los Servicios Sociales: el caso de los centros residenciales para personas mayores. Revista de dirección y administración de empresas, (18), 95-123.

Stanfield, D., \& Beddoe, L. (2013). Social work and the media: A collaborative challenge. Aotearoa New Zealand Social Work, 25(4), 41-51.

Tower, K. (2000). In our own image: Shaping attitudes about Social Work through television production. Journal of Social Work Education, 36(3), 575-585.

Westwood, J. (2013). Media and social work. In A. Worsley, T. Mann, A. Olsen \& E. Mason-Whitehead (Eds.), Key concepts in social work practice (137-141). Thousand Oaks, California: Sage. 
Muriel-Saiz y Martín-Estalayo

Westwood, J. (2014). Social Media in Social Work Education. Northwich, United Kingdom: Critical Publishing.

Zugazaga, C.B., Surette, R.B., Méndez, M., \& Otto, C.W. (2006). Social Worker Perceptions of the Portrayal of the Profession in the News and Entertainment Media: An Exploratory Study. Journal of Social Work Education, 42(3), 621-536. 


\section{OTROS ARTÍCULOS DE PROSPECTIVA No. 30 DE 2020}

\section{EDITORIAL}

Coherencia, integridad y vida cotidiana

Luz Mary Sánchez-Rengifo

\section{ARTÍCULOS}

Trabajo Social y medios de comunicación: perspectivas y posibilidades de encuentro Social

Mercedes Muriel-Saiz

Maribel Martín-Estalayo

Seguridad, afectos y familias. Obstáculos en el proceso de reintegración de personas desmovilizadas de grupos

armados en Santander, Colombia

Jakeline Vargas-Parra

Ángela María Díaz-Pérez

Priscyll Anctil-Avoine

Reflexividad sobre la intervención profesional en duelo con población afectada por el conflicto armado en Colombia

María Cénide Escobar-Serrano

Maritza Charry-Higuera

Natalia Ramírez-Moncada

Ser mujer indígena, náhuatl, casada, migrante, sin trabajo remunerado: una realidad en los albergues jornaleros agrícolas en Colima, México

Nancy Elizabeth Molina-Rodríguez

Tipos y manifestaciones de la violencia de género: una visibilización a partir de relatos de mujeres víctimas en Soacha, Colombia

Diana Carolina Tibaná-Ríos

Diana Alejandra Arciniegas-Ramírez

Ingrid Julieth Delgado-Hernández

Análisis de necesidades en familias monoparentales con jefatura femenina usuarias de servicios sociales de atención primaria en España

Celia María Fernández-Martínez

Manuela Avilés-Hernández

Experiencias de intervención de trabajadoras sociales con trabajadores sexuales masculinos en Bogotá, Colombia Johan Arturo Barrera-Castellanos
Condiciones laborales de trabajadores sociales en hospitales públicos en la provincia de Mendoza,

Argentina

Cecilia Amalia Molina

Yanina Noemi Roslan-Angeloni

Analía Graciela Correa

Viviana Elena Varela

Gubernamentalidad neoliberal: miradas desde las intervenciones del Trabajo Social en el Gran La Plata, Argentina

Paula Mara Danel

Marcela Claudia Velurtas

Agustina María Favero-Avico

Educación superior en Trabajo Social en Chile y formación para la intervención en situación de calle. Desafios desde la evaluación que interventores hacen de sus procesos de práctica pre-profesional

Carlos Alejandro Andrade-Guzmán

Ignacio Andrés Eissmann-Araya

Educación en Derechos Humanos para el Trabajo Social en Chile: una mirada desde los estándares

internacionales

Lury Soledad Reyes-Pérez

Vivianne Soledad Hasse-Riquelme

Luis Marcelo Silva-Burgos

Arriesgar y preservar la vida: derechos humanos, conflicto sociopolítico armado y Trabajo Social en Colombia

Cristian Sebastián Castaño-Orozco

Ricardo Patiño-Martínez

\section{IN MEMORIAM}

Cristina Bautista Taquinás. Mujer indígena Nasa, Trabajadora Social, lideresa del norte del Cauca, Colombia

Alba Nubia Rodríguez-Pizarro

Lady Johanna Betancourt-Maldonado
ARTISTA INVITADO
MALA JUNTA KLAN
Alejandra Gutiérrez-Cárdenas

\section{PROSPECTIVA}

